\title{
Instructional Support for Novice Law Students: Reducing Search Processes and Explaining Concepts in Cases
}

Citation for published version (APA):

Nievelstein, F., Van Gog, T., Van Dijck, G., \& Boshuizen, E. (2011). Instructional Support for Novice Law Students: Reducing Search Processes and Explaining Concepts in Cases. Applied Cognitive Psychology, 25(3), 408-413. https://doi.org/10.1002/acp.1707

DOI:

10.1002/acp.1707

Document status and date:

Published: 20/05/2011

Document Version:

Peer reviewed version

Document license:

CC BY-NC

Please check the document version of this publication:

- A submitted manuscript is the version of the article upon submission and before peer-review. There can be important differences between the submitted version and the official published version of record. People interested in the research are advised to contact the author for the final version of the publication, or visit the DOI to the publisher's website.

- The final author version and the galley proof are versions of the publication after peer review.

- The final published version features the final layout of the paper including the volume, issue and page numbers.

Link to publication

\section{General rights}

Copyright and moral rights for the publications made accessible in the public portal are retained by the authors and/or other copyright owners and it is a condition of accessing publications that users recognise and abide by the legal requirements associated with these rights.

- Users may download and print one copy of any publication from the public portal for the purpose of private study or research.

- You may not further distribute the material or use it for any profit-making activity or commercial gain

- You may freely distribute the URL identifying the publication in the public portal.

If the publication is distributed under the terms of Article 25fa of the Dutch Copyright Act, indicated by the "Taverne" license above, please follow below link for the End User Agreement:

https://www.ou.nl/taverne-agreement

Take down policy

If you believe that this document breaches copyright please contact us at:

pure-support@ou.nl

providing details and we will investigate your claim.

Downloaded from https://research.ou.nl/ on date: 26 Apr. 2023 
Running head: INSTRUCTIONAL SUPPORT FOR NOVICE LAW STUDENTS

Instructional Support for Novice Law Students: Reducing Search Processes and Explaining Concepts in Cases

\section{In Press}

Fleurie Nievelstein ${ }^{\mathrm{a}}$, Tamara van Gog ${ }^{\mathrm{a}, \mathrm{b}}$, Gijs van Dijck ${ }^{\mathrm{c}}$, and Henny P. A. Boshuizen ${ }^{\mathrm{a}}$

${ }^{a}$ Center for Learning Sciences and Technologies, and Netherlands Laboratory for Lifelong Learning, Open University of the Netherlands, Heerlen, The Netherlands

${ }^{\mathrm{b}}$ Institute of Psychology, Erasmus University Rotterdam, Rotterdam, The Netherlands

${ }^{\mathrm{c}}$ Faculty of Law, Tilburg University, Tilburg, The Netherlands

Author Note

Correspondence concerning this manuscript should be addressed to Tamara van Gog, Institute of Psychology, Erasmus University Rotterdam, P.O. Box 1738, 3000 DR Rotterdam, The Netherlands. T: +31 10 40889041; E: vangog@,fsw.eur.nl

Acknowledgements. We would like to thank LL.M. Helma Severeyns-Wijenbergh for developing the materials, the Faculty of Law at Tilburg University for the facilitation of this study, and prof.dr. Huub Spoormans for his helpful suggestions concerning previous drafts of this article. 
Instructional Support for Novice Law Students 2 


\begin{abstract}
Reasoning about legal cases is a complex skill that imposes a high working memory load, especially for novice students. Not only do novices lack necessary conceptual knowledge, searching through the information sources that are used during reasoning can also be assumed to impose a high additional working memory load that does not contribute to learning. Therefore, this study investigated the effects of supporting novice law students' learning by a) providing the meaning of important concepts in the case, and $b$ ) reducing the search process by providing a condensed (relevant articles only) rather than a complete civil code. Results show that performance on a test case (for which they had to use the complete civil code) was significantly better for participants who had used the condensed civil code during learning. Performance on a conceptual knowledge posttest was significantly enhanced when students had received the concept explanations during learning.
\end{abstract}


Instructional Support for Novice Law Students: Reducing Search Processes and Explaining Concepts in Cases

Irrespective of their legal specialization (e.g., solicitor, judge, public prosecutor, legal advisor), reasoning about cases is probably the most important activity for professionals in the domain of law (Blasi, 1995; Lundeberg, 1987; Stratman, 2002; Williams, 1992). Almost daily, they solve problems and make decisions founded on legal rules and documented previous decisions of the court (i.e., jurisprudence/court judgments; Blasi, 1995). In Civil (EuropeanContinental) law, the primary sources of jurisdiction are documented laws, and court judgments on prior cases are used to a lesser degree (Dop, 2003; Gall, 2004). However, when codes or statutes cannot give an unambiguous answer, or when new cases contain similar relevant features as previous cases, judges tend to make their decisions on the interpretation of the codes used in past court judgments (Gall, 2004; Vandevelde, 1996). So in Civil law, legal problems are analyzed in light of generally accepted rules from which a solution can be deduced (Stratman, 2004), and this type of reasoning can therefore be called rule-based reasoning (Vandevelde, 1996). In Common (Anglo-Saxon) law, jurisdiction is based both on court decisions on previous cases as well as statutes. Precedent plays a much more important role in Common law than in Civil law, because the doctrine of stare decisis binds lower courts to base their judgments on decisions on similar cases made by the higher courts of law (Gall, 2004; Marchant, Robinson, Anderson, \& Schadewald, 1993; Vranken, 2006). Therefore, in Common law, cases are mainly analyzed by drawing analogies to past cases and court judgments, and this type of reasoning can be called analogical or case-based reasoning (Sullivan, Colby, Welch-Wegner, Bond, \& Shulman, 2007; Vandevelde, 1996), which is a cyclic and integrated process of solving problems by abstracting the rules, learning form this experience, and solving similar problems by analogy (Aamodt \& Plaza, 1994). Despite those differences between the systems, reasoning about cases 
forms the backbone of instruction in virtually all law school curricula (Sullivan et al., 2007; Vranken, 2006; Williams, 1992).

Research has shown, however, that many law students, and especially novices, experience serious difficulties with reasoning about cases (Nievelstein, 2009; Sullivan et al., 2007). One main reason is that novice students lack the necessary conceptual knowledge to interpret a case (Blasi, 1995; Deegan, 1995; Lindahl, 2004; Nievelstein, Van Gog, Boshuizen, \& Prins, 2008). Moreover, effective use of the information sources (i.e., codes, documented jurisprudence) that are available when reasoning about cases also relies to a large extent on conceptual knowledge, but in addition requires knowledge of how the source is organized. Nievelstein, Van Gog, Boshuizen, \& Prins (2010) showed that novices were not able to use a civil code effectively: Their performance did not improve compared to a condition in which students had no information other than the case description at their disposal. Therefore, the present study investigates two potential forms of instructional support for novice law students' learning to reason about cases: Providing concept explanations and reducing search processes in the information sources that are used during reasoning. Cognitive Demands Imposed by Reasoning about Law Cases

Reasoning about law cases is a complex cognitive task that imposes a high load on working memory, because it requires the integration of different interrelated information elements and the coordination of different cognitive processes (Sweller, Van Merriënboer, \& Paas, 1998): law school students have to read cases, formulate questions, search in information sources for applicable laws and provisions, check whether rules and provisions can be applied to the case, and finally, provide convincing, substantive argumentation to those questions (Blasi, 1995; Sullivan et al., 2007). In integrating and coordinating those different processes, conceptual knowledge plays a pivotal role. Knowledge of relevant legal concepts is required to understand 
the case and to frame the problem in the correct legal context (Deegan, 1995; Lindahl, 2004). Furthermore, to determine the most relevant information in the case, what the underlying legal framework is, and which laws might therefore be most applicable, students should know the formal meaning of legal concepts (Lundeberg, 1987; Sullivan et al., 2007; Vranken, 2006). Two complications arise here. First, students are often hindered by intuitive, everyday ideas about many concepts when they start to study law, which need to be changed into formal meanings (Lindahl, 2004; Lundeberg, 1987; Nievelstein et al., 2008). Second, the meaning of some concepts varies with the context of the case. That is, in a different context, the same concept can have other implications (Lindahl, 2003; Vranken, 2006). An example is the concept 'property' that does not always have the same meaning in the Dutch civil code (Vervoordeldonk, 2006). Depending on the context, it can mean a tangible object, or it can imply the right of ownership. Therefore, the context of the case in which concepts are embedded is important to abstract their exact meaning.

Another difficulty is related to the need to identify potentially applicable laws to the case which also requires searching in information sources such as lawbooks or legal databases containing court judgments. The use of such information sources plays an important role in the legal profession because lawyers need to exactly qualify and verify possible applicable laws and/or court judgments to single cases. The importance of this strict qualification and verification is to achieve equality, generalisation, repeatability, and predictability of jurisdiction (Vranken, 2006). Again, conceptual knowledge is important to understand the information in the sources. However, to be able to search effectively, knowledge of the organization and indexing of the information source is also required. Knowledge about the organization of the Dutch civil code, for example, would be knowing that the code starts with general and ends with particular provisions, that it consists of one part related to 'persons' (i.e., law of persons) and one part 
related to 'properties' (i.e., law of property), et cetera. This knowledge of the organization of information sources might reduce the search space when searching for applicable laws, but novices usually also lack this kind of knowledge. Searching through information sources also imposes a high working memory load, because the information from the case and the information searched for should be kept in mind throughout the search process, and the information that is found also needs to be interpreted in light of the case information and/or in light of other laws or court judgments referred to in the source.

Finally, students need to be able to anticipate arguments from the opposite party, which has different interests (Ashley \& Aleven, 1991; Stratman, 2002; Thagard, 1992). However, research suggests that taking different perspectives may be more difficult under conditions of high cognitive load (Roßnagel, 2000). Moreover, students are often ascribed one specific role (e.g., lawyer party A, lawyer party B, judge) when reasoning about cases, and not stimulated to anticipate on possible actions of people with different roles (Stratman, 2002).

\section{Instructional Support for Novices’ Learning to Reason about Law Cases}

Given the pivotal role conceptual knowledge plays in reasoning about cases, it should be clear that lack of this knowledge seriously hampers novice law students' learning when instruction consists of engaging in reasoning about cases. In addition, lack of conceptual knowledge and knowledge of how information sources are organized probably lead to ineffective search processes when using the information sources. Ineffective search processes impose a high extraneous cognitive load, which may hamper learning (Sweller et al., 1998). This could explain why novice law students in the aforementioned study by Nievelstein et al. (2010) were not able to benefit from the availability of the information source. However, it is unclear from the findings from that study what the most likely cause of the difficulties is, that is, whether (1) lack of 
conceptual knowledge hinders students' understanding of the case, the underlying legal framework, and the information source, (2) the search process in the information source itself while keeping in mind the relevant case information- imposes an ineffective load on working memory and as a result, hinders learning, or (3) it is an interplay of those two possible causes.

The present experiment investigates whether learning to reason about cases is improved by a) providing novice law students with explanations of the meaning of relevant formal concepts (e.g., 'purchase', 'owner', and 'hire agreement') along with the case description, which would help them to make sense of the case information, and b) reducing the search space in the civil code by providing learners with only the articles that represent the rules of law of the code (i.e., condensed civil code) that need to be used when solving the cases we presented. If lack of correct conceptual knowledge leads to learning difficulties, the condition in which concept explanations are added to the case would be expected to lead to better learning than the conditions that did not get concept explanations. If, however, ineffective search processes cause the learning difficulties the conditions in which students can use a condensed civil code would be expected to lead to better learning than the conditions that had to use the complete code. Finally, if both the lack of conceptual knowledge and the ineffective load imposed by the search process are the cause, the condition that was provided with a combination of concept explanations and a condensed civil code would be expected to lead to better learning than the concept explanations only, condensed code only, or control (no concept explanations, complete code) condition.

Method

\section{Participants}

Seventy-nine first-year law students from a Dutch university volunteered to participate in this study. They were novices on the topic of private law (i.e., they had not yet started with the 
introductory course on private law, a subfield of civil law). For their participation, students received a financial compensation of $€ 10$ and a small amount of course credit on a written exam. Design

A 2 × 2 factorial design with the factors Concept Explanations (Yes/No) and Civil Code (Condensed/Complete) was used. This leads to four conditions: 'Concept Explanations Condensed Civil Code' $(n=20)$, 'Concept Explanations - Complete Civil Code' $(n=20)$, 'No Concept Explanations - Condensed Civil Code' $(n=20)$, and 'No Concept Explanations Complete Civil Code' $(n=19)$.

\section{Materials}

Electronic experimental environment. All materials (a pre-test, a post-test, two learning tasks, one test task, and mental effort rating scales) were presented in a web-based electronic experimental environment. The environment logged participants' responses and time-on-task.

Pre-test and post-test of conceptual knowledge. A pre-test and post-test were used to measure conceptual knowledge before and after the experiment. The tests consisted of the 21 concepts (e.g., 'owner', 'transfer of property', and 'gift') that were also used in the problem description of the learning tasks and test task. Students were required to give their definition of the concepts, or to mark 'I do not know' if they did not know the meaning of a concept.

Learning tasks. The learning tasks consisted of two civil law cases with the same underlying theme, namely ownership and transfer of property, but with different contexts. The context of transfer of property (i.e., a pair of skis) in the first learning task had the sequence of hire - sell - gift. That is, person A hired a pair of skis from person $\mathrm{X}$, then sold the skis to person $\mathrm{B}$, who in turn gave the skis to person $\mathrm{C}$ as a present. The context of transfer of property (i.e., high-pressure pistol) in the second learning task had the sequence of hire - gift - gift. That is, person A hired the high-pressure pistol from person X, gave the pistol to person B as a present, 
who in turn, gave the pistol to person $\mathrm{C}$ as a present. The learning tasks appeared in text on the computer screen. Below the learning tasks was a typing window in which students were required to write their argumentation about who became owner of the object after the transfer of the skis and the high pressure pistol respectively. There was no limitation on the number of characters that could be typed in this window. The complete civil code consisted of the civil code collection Dutch legislation (approximately 2400 pages). The condensed civil code consisted of only those articles participants needed -twelve in total- for their reasoning about the cases, copied on seven pages of A4 paper. The concept explanations concerned the same 21 concepts that appeared in the pre-test and post-test. In the concept explanation conditions, definitions of the concept were presented on the right side of the computer screen next to the learning task and were visible continuously until the task was completed.

Test task. The test task consisted of a case that was again about ownership and transfer of property, but the context of transfer of property (i.e., a scooter) in this test task had the sequence of hire - gift - sell. That is, person A hired a scooter from person X, gave the scooter to person B as a present, who in turn, sold the scooter to person C. It was presented in text on the computer screen, with a typing window below the task, in which students were required to write their argumentation about who became owner of the object after the transfer of the scooter. Concept explanations were no longer provided and all participants had to use the complete civil code.

Mental effort rating scale. Invested mental effort was measured using the 9-point subjective rating scale developed by Paas (1992). The scale ranged from very, very low mental effort (1) to very, very high mental effort (9). This rating scale is widely used in educational research (Paas, Tuovinen, Tabbers, \& Van Gerven, 2003; Van Gog \& Paas, 2008). Mental effort reflects the actual cognitive load (i.e., the cognitive capacity that is actually allocated to accommodate the demands imposed by the task; Paas et al., 2003). 


\section{Procedure}

The experiment was run in two-hour group sessions with approximately 20 students per session in a computer room at the law school. In each session, participants were randomly assigned to conditions (i.e., conditions were not tied to sessions), by having the experiment leader randomly hand out login codes that ascribed participants to one of the four conditions. With login codes that applied to the condensed civil code condition, participants also received a version of the condensed code. The other students were told to use their copy of the complete code, which all participants had been asked to bring along. The students worked individually and at their own pace. Students first received a short oral explanation about the experimental procedure. They were instructed to log on to the electronic learning environment and told to follow the directions on the screen. All students first completed the pre-test. Then, all students worked on the same two learning tasks one after another, with or without the support of the concept explanations and with the instruction to either use the complete or the condensed civil code, depending on their assigned condition. Before starting the test task, students in the condensed civil code condition had to hand in the condensed code to the experiment leader, and students in all conditions were instructed to use their complete civil code during the test task. On both the learning and the test tasks, students had to read the case, search in the condensed or complete code for applicable rules and laws, check whether rules and laws were applicable to the case, and provide convincing argumentation on the question of who became owner of the object after that particular sequence of transfer of property. After completing the test task, they received the post-test. Students had to mark how much mental effort they invested in the pre-test, in each learning task, in the test task, and in the post-test on the 9-point rating scale that appeared on the computer screen directly after completion of each of those tests or tasks. After rating the mental effort on the post-test, participants were automatically logged out of the system. 


\section{Data analysis}

Concept definitions provided in the pre-test and post-test were rated according to their formal definitions in a Dutch legal dictionary (Algra et al., 2000). The formal definitions of the concepts consisted of one, two, or three parts. For each of these parts correctly mentioned, one point was assigned. A total of 34 points could be gained.

Performance on the test task was analysed according to a scoring model developed by a private law professor, comparable to the models used to score examinations. It consisted of 30 different elements (specific for this case) which should be elaborated upon in order to provide a substantiate conclusion on the question of who became owner of the object and why. Examples of elements are: a) 'Is the delivery valid?' and b) 'Has the delivery taken place other than for free?'. The weight (number of points to be gained) ascribed to each argument, depended on the importance of the argument to reach the correct solution. Points were only ascribed if the correct element was mentioned and if it was unambiguously mentioned why the element was or was not applicable to this specific case. In total 100 points could be gained.

Two raters independently scored $10 \%$ of the protocols. The Intraclass Correlation Coefficient (ICC; Shrout \& Fleiss, 1979) was .78 for the prior knowledge test and .83 for the test case. Because this was adequate, the remaining protocols were scored by one rater and in the analyses we used the scores of the rater who scored all protocols.

\section{Results}

Table 1 presents the means and standard deviations of the performance, mental effort, and time on task data per condition. For the analyses reported here, Cohen's $f$ is provided as a measure of effect size with $.10, .25$, and .40 , corresponding to small, medium, and large effects, respectively (Cohen, 1988). 
Due to a server connection failure, pre-test data of eleven participants were not logged (i.e., 'Concept Explanations - Condensed Civil Code' $n=4$, 'Concept Explanations - Complete Civil Code' $n=1$, 'No Concept explanations - Condensed Civil Code' $n=3$, and 'No Concept Explanations - Complete Civil Code' $n=3$ ), those participants were excluded from the pre-test analysis. A one-way ANOVA showed no significant differences between groups on the pre-test $F(3,64)=1.19, p>.20$, so students in the different conditions did not differ on prior knowledge of concepts.

Test performance. A 2 × 2 ANOVA with factors 'Concept Explanations' and 'Condensed Civil Code' showed a significant main effect of 'Condensed Civil Code' on test task performance $F(1,75)=15.46, M S E=147.01, p<.001, f=.11$, indicating that students who had used the condensed code during the learning phase $(M=23.37, S D=14.42)$ scored better on the test (using the complete code) than students who had used the complete code during learning $(M=$ $12.74, S D=9.67)$. There was no significant main effect of 'Concept Explanations', $F(1,75)=$ $3.40, M S E=147.01, p=.069$, nor a significant interaction effect, $F(1,75)=0.97, M S E=147.01$, $p>.20$.

Knowledge gain. Due to a server connection failure, the post-test data from eight participants were lost (i.e., 'Concept Explanations - Condensed Civil Code' $n=3$, 'No Concept Explanations - Condensed Civil Code' $n=2$, and 'No Concept Explanations - Complete Civil Code' $n=3$ ). Combined with the lost pre-test data (i.e., for some students pre-test data and for others post-test data was lost, and for some students both), pre- to post-test knowledge gain could be computed for 65 participants. A 2 × 2 ANOVA, with the factors 'Concept Explanations and 'Condensed Civil Code' only showed a significant main effect of 'Concept Explanations' on preto post-test knowledge gain, $F(1,61)=56.01, M S E=9.58 p<.001, f=.94$, indicating that students who had received the concept explanation during the learning phase $(M=7.06, S D=$ 
3.81) scored better on the test than students who had not been given the explanations $(M=1.25$, $S D=2.11)$

Mental effort. A 2 x 2 ANOVA, with the factors 'Concept Explanations' and 'Condensed Civil Code' showed no significant differences in mental effort invested in any of the experimental phases (pre-test: $F(3,64)<1$; learning tasks: $F(3,75)<1$; test task: $F(3,75)<1$; conceptual knowledge post-test: $F(3,67)<1)$.

Time on task. A 2 × 2 ANOVA, with the factors 'Concept Explanations' and 'Condensed Civil Code' showed no significant differences in time on task in any of the experimental phases (pre-test: $F(3,64)<1$; learning tasks: $F(3,75)<1$; test task: $F(3,75)<1$; conceptual knowledge post-test: $F(3,67)<1)$.

\section{Discussion}

This experiment investigated whether novice law students' learning was enhanced by providing them with instructional support consisting of concept explanations, a condensed civil code, or both, while learning to reason about cases. Performance on a test case under normal conditions (i.e., without explanations and using a complete code) was improved when students made use of a condensed civil code that contained only relevant articles during the learning phase. Conceptual knowledge gain, however, was higher when students had been provided with concept explanations during the learning phase. It is important to note that those performance benefits were obtained with the same amount of mental effort investment, that is, the cognitive processes in which effort was invested were more useful for learning to reason about the case and learning conceptual knowledge in the condensed code and concept explanations conditions, respectively (Van Gog \& Paas, 2008).

The findings on test case performance suggests that reducing the ineffective cognitive load imposed by search processes enables students to learn better. Using a condensed code 
reduces the search space, thereby preventing ineffective search processes that arise from not knowing which articles are relevant and not knowing how the information source is organized. Rather than losing precious cognitive resources on searching through large amounts of information, students' attention can be entirely devoted to making sense of the relevant information in the code in relation to the case (i.e., effective or, germane cognitive load; Sweller et al., 1998). Of course, ultimately, students will need to learn to use the complete code, and need to acquire knowledge of how it is organized. However, it is possible that they may learn this from repeated exposure to parts of the code, as on the test case, all students had to use the complete code, which posed no problems for the students who learned with the condensed code. If it needs to be explicitly taught, it might be more effective to teach students the ability to find relevant information by slowly building this up, initially using very condensed codes, and gradually increasing the amount of information that needs to be searched through.

Even though the condensed code conditions performed better on the test than the complete code conditions, the average test performance scores in this group show that there is still a lot of room for improvement. The interventions studied here were only focused on support at the conceptual level and on the search process level, not on the reasoning process itself. Students may profit from a form of support that not only helps them to see which articles in the civil code are relevant to apply to a specific case, but also why those articles are relevant (i.e., what is the underlying legal framework) and how they can be applied, because argumentation plays an important role in reasoning about cases (Deegan, 1995; Lundeberg, 1987). An interesting question for future research therefore, is whether support for the entire reasoning process is more effective. Such support could be provided for example, by worked examples, process worksheets, or by decision support systems (Hummel, Paas, \& Koper, 2004; Nadolski, Kirschner, \& Van Merriënboer, 2005). 
Support consisting of concept explanations along the case did not improve students' reasoning, but it was useful: it improved knowledge of those concepts (higher pretest to posttest gain) compared to students who had not received them. Given the pivotal role conceptual knowledge plays in legal reasoning, this might be an interesting instructional manipulation to enhance that knowledge, although future research should explore why an increase in conceptual knowledge relevant for the test case, did not improve reasoning on that case. Possibly, students only superficially learned the concepts, because the meaning of each single concept was given without any further information about the relationship(s) with other concepts and the concept's implication(s) in this specific context. In other words, they may have learned the concepts, but may not have developed deep understanding necessary to be able to apply conceptual knowledge during reasoning. Perhaps additional forms of support such as concept maps, that also show the significant relationship(s) between concepts, might improve such understanding and hence, reasoning.

In sum, this study suggests that both the use of condensed codes and the provision of concept explanations during learning may be interesting instructional support techniques for law education. Although this study was conducted in the Civil law system, in the subfield of private law, the problems related to conceptual knowledge and search processes for novice students are quite general, so the same principles would probably apply in other subfields or in Common law. For example, reducing the amount of information that needs to be searched might be very helpful when novice students are asked to reason about the application of statutory provisions to a problem in Common law, or when they need to search databases or books for applicable jurisdiction. 


\section{References}

Aamodt, A., \& Plaza, E. (1994). Case-based reasoning: Foundational issues methodological variations, and system approaches. AI Communications, 7, 39-59.

Algra, N. E., Barmentlo, D. G., Beelen, S. T. M., Van den Bergh, A., Boel, F. C., De Boer, A. H., et al. (2000). Juridisch woordenboek [Legal dictionary]. Nijmegen, The Netherlands: Ars Aequi.

Ashley, K. D., \& Aleven, V. (1991). Toward an intelligent tutoring system for teaching law students to argue with cases. Proceedings of the Third International Conference on Artificial Intelligence and Law (pp. 42-52). New York: ACM Press.

Blasi, G. (1995). What lawyers know: Lawyering expertise, cognitive science, and the functions of theory. Journal of Legal Education, 45, 313-397.

Cohen, J. (1988). Statistical power analysis for the behavioural sciences $\left(2^{\text {nd }}\right.$ ed.). Hillsdale, NJ: Erlbaum.

Deegan, D. H. (1995). Exploring individual differences among novices reading in a specific domain: The case of law. Reading Research Quarterly, 30, 154-170.

Dop, A. (2003). Common law versus Civil law. Linguaan, 3, 1-8.

Gall, G. L. (2004). The Canadian legal system. Scarborough, Ont.: Carswell.

Hummel, H. G. K., Paas, F., \& Koper, E. J. R. (2004). Cueing for transfer in multimedia programmes: Process worksheets versus worked-out examples. Journal of Computer Assisted Learning, 20, 387-397.

Lindahl, L. (2003). Operative and justificatory grounds in legal argumentation. Associations, 7 , $185-200$.

Lindahl, L. (2004). Deduction and justification in the law: The role of legal terms and concepts. Ratio Juris, 17, 182-202. 
Lundeberg, M. A. (1987). Metacognitive aspects of reading comprehension: Studying understanding in case analysis. Reading Research Quaterly, 22, 407-432.

Marchant, G., Robinson, J., Anderson, U., \& Schadewald, M. (1993). The use of analogy in legal argument: Problem similarity, precedent, and expertise. Organizational Behavior and Human Decision Processes, 55, 95-119.

Nadolski, R. J., Kirschner, P. A., \& Van Merriënboer, J. J. G. (2005). Optimizing the number of steps in learning tasks for complex skills. British Journal of Educational Psychology, 75, $223-237$.

Nievelstein, F. (2009). Learning law: Expertise differences and the effect of instructional support. Doctoral Dissertation, Open University of The Netherlands, Heerlen, The Netherlands.

Nievelstein, F., Van Gog, T., Boshuizen, H. P. A., \& Prins, F. J. (2008). Expertise-related differences in ontological and conceptual knowledge in the legal domain. European Journal of Cognitive Psychology, 20, 1043-1064.

Nievelstein, F., Van Gog, T., Boshuizen, H. P. A., \& Prins, F. J. (2010). Effects of conceptual knowledge and availability of information sources on law students' legal reasoning. Instructional Science, 38, 23-35.

Paas, F. (1992). Training strategies for attaining transfer of problem-solving skill in statistics: A cognitive load approach. Journal of Educational Psychology, 84, 429-434.

Paas, F., Tuovinen, J. E., Tabbers, H., \& Van Gerven, P. W. M. (2003). Cognitive load measurement as a means to advance cognitive load theory. Educational Psychologist, 38, $63-71$. 
Roßnagel, C. (2000). Cognitive load and perspective-taking: Applying the automatic-controlled distinction to verbal communication. European Journal of Social Psychology, 30, 429445.

Shrout, P. E., \& Fleiss, J. L. (1979). Intraclass correlations: Uses in assessing rater reliability. Psychological Bulletin, 86, 420-428.

Stratman, J. F. (2002). When law students read cases: Exploring relations between professional legal reasoning roles and problem detection. Discourse Processes, 34, 57-90.

Stratman, J. F. (2004). How legal analysts negotiate indeterminacy of meaning in common law rules: Toward a synthesis of linguistic and cognitive approaches to investigation. Language and Communication, 24, 23-57.

Sullivan, M. W., Colby, A., Welch-Wegner, J., Bond, L., \& Shulman, L. S. (2007). Educating lawyers. San Francisco: Jossey-Bass.

Sweller, J., Van Merriënboer, J. J. G., \& Paas, F. (1998). Cognitive architecture and instructional design. Educational Psychology Review, 10, 251-296.

Thagard, P. (1992). Adversarial problem solving: Modeling an opponent using explanatory coherence. Cognitive Science, 16, 123-149.

Vandevelde, K. J. (1996). Thinking like a lawyer: An introduction to legal reasoning. Boulder, CO: Westview Press.

Van Gog, T., \& Paas, F. (2008). Instructional efficiency: Revisiting the original construct in educational research. Educational Psychologist, 43, 16-26.

Vervoordeldonk, J. M. (2006). Zaken zijn zaken - of toch niet? Een juridisch-terminologisch onderzoek naar plaats en betekenis van centrale begrippen uit het vermogensrecht [Cases are cases - or aren't they? A judicial-terminology study of place and meaning of central 
concepts in right of property]. Unpublished Master's thesis, Open University of the Netherlands, Heerlen, the Netherlands.

Vranken, J. B. M. (2006). Exploring the jurist's frame of mind. Deventer, The Netherlands: Kluwer.

Williams, S. M. (1992). Putting case-based instruction into context: Examples from legal and medical education. Journal of the Learning Sciences, 2, 367-427. 